\title{
A MILAGROSA ECONOMIA DA RELIGIĨO: UM ENSAIO SOBRE CAPITAL SOCIAL
}

\author{
David Lehmann \\ University of Cambridge - Reino Unido
}

Resumo: Diz-se freqüentemente que a religião contribui para o capital social, embora sob circunstâncias específicas. Os movimentos religiosos de renovação são comuns entre populações marginalizadas e de baixa renda e parecem ser, freqüentemente, os únicos a construírem instituições em circunstâncias de extrema pobreza e decadência ou vazio institucional; os movimentos religiosos apresentam numerosas características não-democráticas, tais como hierarquias autoritárias e uma forte pressão sobre seus fiéis para que façam sacrifícios e contribuam com dinheiro. Este estudo explora as implicações teóricas dessas observações aparentemente paradoxais, mediante a adoção da abordagem da teoria da escolha racional, junto com o conceito de poder e com um conceito de capital social que põe a ênfase na transparência e na construção de instituições democráticas na sociedade em geral. O argumento é ilustrado pelos exemplos das igrejas evangélicas da América Latina e do judaísmo ultra-ortodoxo, e conclui apresentando a visão que, embora a contribuição dos movimentos religiosos à democratização geral seja limitada, isso não é suficiente para menosprezar o que eles fazem por seus próprios seguidores.

Palavras-chave: capital social, confiança, escolha racional, movimentos religiosos.

Abstract: Religion is often claimed to contribute to social capital, though under certain circumstances; it is widely recognized that movements of religious renewal and revival are mostly commonly observed among low-income, and marginalized populations, and sometimes seem to be the only institution-builders in circumstances of extreme poverty and institutional decay or vacuum; religious movements exhibit numerous undemocratic features: authoritarian hierarchies, strong pressures on followers to make sacrifices, to conform, and to contribute money. This paper explores the theoretical implications and support for these apparently paradoxical observations by adopting a rational choice approach augmented by the concept of power, and a concept of social capital which emphasizes transparency and the building of democratic institutions in society as a whole. The argument is illustrated by examples from Latin American evangelical churches and ultra-Orthodox Judaism, and concludes 
with the view that while the contribution of religious movements to democratization at large is limited, this is not a sufficient reason for belittling what they can do for their own followers.

Keywords: rational choice, religious movements, social capital, trust.

A religião pode ter um efeito sadio na sociedade civil, encorajando seus membros a participar de cultos, passar tempo com suas famílias e aprender as lições morais próprias das tradições religiosas. Mas o impacto da religião na sociedade poderá diminuir se esse for o único papel que ela desempenhar. (Wuthnow 1999, p. 362).

O título deste artigo é aparentemente paradoxal: por que, com tanta freqüência, as únicas instituições que parecem surgir em meio às circunstâncias tão desfavoráveis das populações pobres e excluídas são as instituições religiosas? É esse o "milagre” do nosso título, e responderei à pergunta relacionando-a à contribuição dos movimentos religiosos para a geração de capital social. Inevitavelmente, como todas as grandes questões, essa pergunta foi formulada de forma demasiado direta, e devemos, portanto, explorar as questões analíticas a fim de reformulá-la.

Foi difícil não notar, em dezembro de 2004, que à medida que o tsunami retrocedia, os únicos edifícios que permaneciam em pé eram freqüentemente as igrejas e as mesquitas. Tal imagem de permanência e estabilidade em meio ao caos é completada por relatos, em documentos e na imprensa, sobre as favelas no Rio de Janeiro, onde os gangsters inspiram medo e as únicas figuras respeitadas são os pastores, muitos deles antigos traficantes: até os pistoleiros os respeitam. ${ }^{1}$ Como explicar então que é precisamente em tais circunstâncias que as igrejas evangélicas, e talvez até os locais de ensino religioso, proliferam aparentemente com maior rapidez? Mas até onde pode ir essa imagem de confiança em meio a tanta desconfiança? As circunstâncias desfavoráveis referem-se à falta de instituições que operem na base da regras perenes sujeitas

1 O documentário de João Salles, História de uma Guerra Particular, complemento do livro Cidade de Deus e do filme homônimo. Há abundantes provas de que a maior parte dos fiéis das igrejas evangélicas na América Latina provêm das camadas mais pobres da sociedade (Lehmann, 1996). Já na África, as igrejas tendem a proliferar entre as camadas sócias um pouco acima daquelas mais pobres (Garner, 1998, 2000).

Horizontes Antropológicos, Porto Alegre, ano 13, n. 27, p. 69-98, jan./jun. 2007 
a uma aplicação desinteressada - um ambiente no qual o limite entre as esferas privada e pública é muito menos claro que no modelo-padrão da modernidade e da sociedade secular, e onde as relações de clientelismo são a forma dominante de poder e autoridade, inibindo o comportamento universalista baseado na obediência a leis e estimulando as relações de dependência pessoal. Em termos mais práticos, elas evocam uma violência e uma pobreza profundamente enraizadas, que persistem a despeito dos esforços dos governos e das ações das ONGs, e apesar também das grandes transformações sociais ocorridas tanto local quanto globalmente.

Além disso, em tais circunstâncias, as organizações religiosas enfrentam interesses hostis de todos os tipos, incluindo os dos proprietários de terra que se opõem a quaisquer formas de organização por parte de seus trabalhadores, de outras organizações religiosas, de criminosos e gangsters (apesar das exceções já mencionadas) e até mesmo por parte de leigos e ateus.

\section{Instituicões e capital social}

A idéia de capital social, da forma como foi originalmente formulada por Coleman (1988), referia-se principalmente à explicação das conquistas educacionais (capital humano), em termos do envolvimento dos pais dos estudantes e da densidade e estabilidade de suas redes familiares e sociais. O desenvolvimento do termo, por Putnam, estendeu sua abrangência às relações entre o intenso associacionismo cívico (muito além da família) e a transparência institucional e a confiança na sociedade abrangente. No livro Making Democracy Work (Putnam et al., 1993), há um maior equilíbrio entre associativismo e transparência institucional do que na obra posterior e mais famosa, intitulada Bowling Alone (Putnam, 2000), a qual põe a ênfase na participação, embora sem ignorar a transparência. A participação tem múltiplas facetas: um dos contrastes é entre o que poderia ser denominado "real" e aquilo que é considerado "virtual": algumas pessoas assistem a reuniões, tendem a procurar amigos e parentes, tornam-se voluntários da Cruz Vermelha local, vão à igreja, à mesquita ou à sinagoga, ajudam a organizar as feiras de verão da escola local e assim por diante. Essas são formas de participação que implicam um comprometimento de tempo e também um envolvimento pessoal, pois a pessoa é vista em público como um membro ativo. Tal participação real pode ser ainda subdividida de uma forma que não é irrelevante para nosso 
debate: há voluntários que não participam das tomadas de decisões: eles ajudam e sem dúvida doam recursos, mas não se envolvem nas tomadas de decisões nem no manejo das atividades; isso fica por conta da política da organização. A participação virtual é ligeiramente diferente: ela é responsável por uma parte cada vez maior dos membros associados e pelos milhões que contribuem com seus dízimos, mas não assistem às reuniões nem participam publicamente de nenhuma forma. Eles contribuem com organizações que são dirigidas por profissionais e têm suas sedes nas grandes cidades, e cuja função é fazer o lobby da igreja. Ao analisar, em Bowling Alone, esse aspecto da realidade norte-americana, Putnam (2000) expressa algumas dúvidas sobre se tal participação contribui significativamente para o capital social, e preocupa-se com o fato de que ela acentua a política partidária: localmente, apenas os "verdadeiros crentes” participam, enquanto em nível nacional grupos de advocacia dominados por profissionais - nas palavras de Theda Skocpol (apud Putnam, 2000, p. 344) juntam grandes somas de dinheiro e tendem a ressaltar alguns problemas e aumentar suas diferenças. Putnam (2000, p. 58 e seguintes) oferece amplas evidências do declínio da participação "real” no último terço do século XX nos Estados Unidos, e expressa sua justificada preocupação com a saúde democrática da nação.

Nesse contexto, a contribuição da participação religiosa para a criação e manutenção do capital social é obviamente interessante, tanto nos Estados Unidos, por serem um país conhecido por seus altos níveis de observância religiosa por parte da população - especialmente se comparado ao Ocidente europeu como em países pobres ou de renda média onde são observados altos níveis de observância religiosa ou crença - que não são necessariamente a mesma coisa (Inglehart; Norris, 2004).

Os países que se caracterizam pela pobreza extrema freqüentemente apresentam altos níveis de participação religiosa, ou melhor, envolvimento religioso, lado a lado com aquilo que poderia ser chamado de degré zero de vida cívica institucional. Essa correlação caricaturada, claro, levanta inúmeras questões sobre o tipo de envolvimento e de crença (desde cultos de possessão ao alto catolicismo ao estilo do Opus Dei), mas mesmo se nos restringimos à religião institucionalizada, o surgimento do cristianismo evangélico na África e na América Latina merece consideração como evidência prima facie da contribuição da religião para o capital social. O capítulo sobre participação religiosa de Bowling Alone de Putnam, entretanto, cria as bases da dúvida. Ele mostra níveis altos e sustentados de envolvimento na vida associativa por parte das 
pessoas que professam uma religião, mas também mostra que tal envolvimento concentra-se entre os evangélicos, e os evangélicos têm uma tendência a se fechar e reforçar suas comunidades, mas a não envolver-se com o resto da sociedade, embora existam exceções (Putnam, 2000, p. 78). E, posteriormente, em nota de rodapé, acrescenta que "as igrejas que se organizam em congregações, tais como as denominações protestantes, tendem a oferecer mais oportunidades para que seus paroquianos construam habilidades cívicas do que as igrejas organizadas hierarquicamente, incluindo a católica, e as denominações evangélicas" - baseado em Verba et al. (1995) - (Putnam, 2000, p. 494).

A isso, eu acrescentaria que os padrões de organização e liderança reforçam o contraste e acrescentam outra característica: as igrejas evangélicas são organizadas diferentemente de outros tipos de igreja, como nota Putnam, e diferentemente também do modelo padronizado de associação cívica. A autoridade tende a estar concentrada em um indivíduo que não está sujeito às decisões tomadas pela participação: ele, ou ocasionalmente ela, é, afinal de contas, um líder carismático no sentido forte, ou ao menos literal, do termo, e se o pastor perde a confiança dos fiéis, estes fecham as carteiras e vão embora. Os fiéis pagam seus dízimos, mas eles não designam o pastor. O mesmo aplica-se às organizações fundamentalistas judaicas: no chassidismo, a autoridade parte do rebbe ou do comitê central (como nas comunidades do Chabad-Lubavitch), não da congregação; entre outros ultra-ortodoxos, ${ }^{2}$ a vida gira em torno do yeshiva, que é controlado por seu líder; e cada vez mais encontramos rabinos empresários que conseguem criar uma comunidade de seguidores que sobreviverá até que seu líder desista ou morra, ou, talvez, perca seu “toque”, como acontece com os pastores evangélicos. Em tais circunstâncias, entre os judeus, os comitês e procedimentos geralmente existem para manejar as premissas da sinagoga ou a atividade de caridade, mas essa atividade democrática e institucional não se estende à escolha de um oficiante da religião. Por outras

\footnotetext{
2 As diferenças entre os chassidim - que apresentam uma tendência mais marcada ao misticismo - e, em termos muito gerais, os outros - freqüentemente conhecidos como "lituanos" - poderia ser o assunto de um longo livro (ainda não escrito). Ambas as categorias mudaram grandemente no período do pós-Segunda Grande Guerra e continuam a mudar. Os lituanos são conhecidos por essa denominação por causa do método de estudos do Talmude desenvolvido em yeshivot em Vilna e difundido pela Europa oriental a partir do final do século XVIII. Para eles, a principal instituição é o yeshiva, mas suas lealdades - e principalmente, suas escolhas de parceiros para casamento ocorrem dentro da comunidade lituana geral, não dentro da comunidade local. Os yeshivot tendem a ser independentes e a não dominar a vida privada dos membros da comunidade.
}

Horizontes Antropológicos, Porto Alegre, ano 13, n. 27, p. 69-98, jan./jun. 2007 
palavras, os níveis de democracia entre os ultra-ortodoxos (chassidim e lituanos), no que concerne à organização religiosa, são baixos; por outro lado, há uma grande preocupação de ter um gerenciamento dos corpos de caridade com base nos comitês e na participação, mesmo quando eles resultam de uma organização religiosa centralizada. Poderia se dizer algo semelhante sobre a Igreja católica, onde as organizações laicas têm um antigo e profundo papel histórico fundamental na organização da religião popular, papel esse que não é controlado pelo clero. Todavia, entre evangélicos e fundamentalistas, embora as bases locais da lealdade possam dar uma aparência de democracia, o pastor centraliza a liderança religiosa e administrativa e nele repousa toda a importância da autoridade financeira. Os pastores pentecostais das pequenas igrejas retêm o controle e, freqüentemente, a posse dos estabelecimentos, e as doações são feitas direta ou indiretamente a eles, para pagar seus salários. Até mesmo na vasta Igreja Universal do Reino de Deus, de origem brasileira, com seus milhões de fiéis em todo o mundo e seu gerenciamento altamente centralizado, não está ainda claro se a posse do seu canal de televisão, TV Record, é da igreja ou de ser líder, Edir Macedo (Birman; Lehmann, 1999).

Essa preocupação com a administração impessoal aparece no livro de Putnam (Putnam et al., 1993) sobre a Itália, onde o autor concentra-se mais no tema da confiança e sua importância para o desenvolvimento de instituições modernas do que no assunto do capital social, o qual aparece apenas na última parte da obra como uma variável explanatória. Em relação à questão da regionalização italiana, - que é o prisma sob o qual Putnam examina a cultura política italiana - o autor mostra que enquanto no Sul da Itália, com sua política impulsionada por patrocínios e seu modelo de lealdades sociais girando em torno da família e do parentesco ampliado, o governo regional teve dificuldades em estabelecer as bases da legitimidade para a administração estadual moderna, no Norte, com sua tradição de participação popular, tais dificuldades eram bem menores. As coisas são, logicamente, mais complicadas, ${ }^{3}$ mas era esse o

\footnotetext{
${ }^{3}$ Logo que o livro foi publicado, todo o sistema político italiano foi engolido por uma cadeia de escândalos de corrupção conhecidos como inquéritos mani pulite, e isso levou finalmente a uma desestruturação total dos partidos da forma como eles estavam organizados até o momento: os democrata-cristãos, os socialistas e os comunistas foram dissolvidos; o escândalo teve inicio não no Sul, mas no Norte da Itália, a partir de negociações envolvendo o prédio do metrô de Milão, por exemplo. De todas maneiras, seria errado tirar conclusões sobre as relações sociais nas ruas e bairros, a partir desses fatos envolvendo a elite.
}

Horizontes Antropológicos, Porto Alegre, ano 13, n. 27, p. 69-98, jan./jun. 2007 
centro do argumento. Segundo Putnam, hoje em dia, as igrejas evangélicas e as seitas fundamentalistas compartilham, em certa medida, dessas características do Sul da Itália: a autoridade pode não estar totalmente baseada na família, mas ela é personalizada na figura do pastor. Na Assembléia de Deus, no Brasil, por exemplo, o presidente da convenção estadual, que é, de fato, o locus do poder (ao invés da organização nacional, que é a confederação sem laços muito fortes), pode permanecer no cargo por décadas, e não surpreenderia se passasse o cargo a seu filho (Lehmann, 1996). No chassidismo, a sucessão dinástica é a regra; já entre outros ultra-ortodoxos, os líderes não são pessoas da comunidade, senão pessoas equivalentes ao líder principal de uma instituição educacional. Na Igreja da Inglaterra, ou na Igreja católica, os procedimentos são mais elaborados e, presumivelmente, mais transparentes, embora ainda a voz dos leigos seja secundária ou, no catolicismo, ignorada. Mas em ambas as igrejas os paroquianos e seguidores contam com um espaço mais ou menos amplo dentro das instituições, onde há pouca ou nenhuma interferência da hierarquia. Assim, as organizações de caridade, o manejo de celebrações, as Comunidades Eclesiais de Base, as escolas dominicais, etc. são manejadas com graus variados de independência do controle hierárquico. As grandes instituições têm, de fato, mecanismos para prevenir abusos de poder. Entretanto, esses recursos podem não ser usados adequadamente ou quando necessário, como mostram os escândalos em que se viram envolvidas a Igreja dos Estados Unidos, a Igreja Irlandesa, outras dioceses católicas e os Legionários de Cristo nos últimos anos, além da indiferença enfrentada por freiras africanas que procuravam algum tipo de compensação pela exploração sexual a que foram submetidas pelos sacerdotes (Cornwell, 2004): nas organizações fundamentalistas e pentecostais, nas igrejas cristãs e judaicas não há como recorrer do abuso do poder. Elas têm líderes poderosos, e, aparentemente, os fiéis confiam neles; entretanto, a palavra "confiar" precisa ser analisada: eles confiam em seus líderes enquanto indivíduos, não em sua qualidade de líderes produzidos e circunscritos pelo aparato institucional que regula o exercício de sua autoridade.

Há, portanto, uma tensão estrutural no modelo de capital social, entre confiança e participação. Na medida em que a confiabilidade das instituições depende de sua impessoalidade, quanto mais confiáveis elas se tornam, menos participativas e mais burocráticas elas são - levando, nos casos extremos, à participação virtual e a uma ausência de envolvimento pessoal. Na visão de Putnam, isso não alimenta nem reflete capital social, embora, na perspectiva de outros autores, enfraqueça o apelo das igrejas mais institucionalizadas. Tam- 
bém é verdade que Putnam acha o tipo de capital social que os evangélicos promovem partidário demais, até mesmo excludente: não contribui com a comunidade como um todo. Ao invés disso, pelos menos enquanto promotor de capital social, Putnam aprova uma versão mais "fria”, na qual as pessoas participam em diversos campos de atividades e mediante diversas redes, expandindo a prática da associação e do debate civilizado. Nessa versão, as associações estão mais institucionalizadas: elas têm comitês com secretários que se alternam, eleições e lideranças compartilhadas, além de funções diretivas divididas entre vários membros. Simultaneamente, Putnam (2000, p. 341) vê benefícios públicos (embora ele não use esse termo) na participação pessoal. A participação cara a cara leva as pessoas a se envolverem entre si, enquanto que a participação não pessoal mediante telefonemas ou grandes encontros (embora não mencione os últimos) não oferece um espaço de "trocas verdadeiras” nem de "feedback democrático", estimulando e recompensando, ao contrário, instâncias polarizadas e não comprometidas. A isso eu acrescentaria que há muito na associação cívica que requer que nos posicionemos e apareçamos publicamente como pessoas públicas, algo para o qual a participação face a face não necessariamente nos prepara. Pode ser que algumas pessoas prefiram permanecer no interior de seus grupos de amigos, criando um limite quase psicológico à quantidade de vida pública que uma comunidade ou uma sociedade podem chegar a experimentar. Pode também ser que exista, apenas dentro de certos limites, uma compensação entre as formas mais e menos quentes de participação.

Portanto, é necessário refinar as variáveis que estamos procurando relacionar e os indicadores que nos permitem seguir tais variáveis. De um lado, formas quentes e não tão quentes de participação podem se misturar de diversas formas e, de outro, havendo pouco a ganhar ao se perguntar como a religião, em termos gerais, pode estimular a confiabilidade e o capital social, devemos nos questionar de que maneira diversas variedades de instituições religiosas e, especialmente, de autoridade religiosa, ajudam na construção da confiança: alguns casos, como menciona Putnam, podem ser quentes demais para que nos sintamos à vontade, enquanto outros, que devido à sua institucionalização podem contribuir mais para o bem geral, podem, de fato, não ser suficientemente quentes para alimentar a participação e assim tender contra a inovação e a aceitação de possíveis riscos.

Uma leitura de Wuthnow (1988) poderia indicar que a religião institucionalizada leva consigo a semente de uma variedade "mais quente” o 
que levaria à hipótese que aquilo que alguns poderiam haver considerado uma "evolução" da seita para a denominação, é apenas um lampejo de um movimento cíclico mais prolongado, no qual desprendimentos de certos setores de algumas denominações são fenômenos que se repetem, como é a institucionalização das seitas. Isso é ilustrado pelo surgimento de igrejas evangélicas a partir de denominações religiosas norte-americanas no período posterior à Segunda Grande Guerra e, posteriormente, pela separação gradual de uma direita mais politizada dentro dos movimentos evangélicos. Os evangélicos cresceram em número de membros e de pastores - por exemplo, a Assembléia de Deus, que cresceu 18\% entre 1952 e 1962 (acrescentando 2 mil novas igrejas), tinha, em 1980, 13 clérigos e 27 igrejas para cada mil membros, em comparação aos metodistas, com seus 4 clérigos e 4 igrejas. Isso reflete uma relação muito íntima e pessoal entre os clérigos evangélicos e seus rebanhos de menos de cem membros em cada igreja (Wuthnow, 1988). Wuthnow descreve três momentos: primeiro, uma ruptura nas igrejas institucionalizadas como a metodista, decorrente de excessiva liberalidade de suas lideranças, as quais estavam defasadas das crescentes inclinações evangélicas dos seus membros; posteriormente, uma virada para a esquerda entre as gerações influentes dos evangélicos durante a década de 1960, em concordância com a crise nacional e o rápido crescimento do número de pessoas com educação universitária entre seus membros e, mais tarde, uma nova divisão que deu origem ao que veio ser conhecido como a direita cristã, liderada pelos televangelizadores e outros que eram menos céticos em relação ao envolvimento político partidário em períodos eleitorais do que as gerações anteriores de evangélicos.

As mudanças, dissidências e confluências ocorrem ao longo e entre as rupturas, que mudam de caráter de uma geração para a seguinte: num primeiro momento, as divisões parecem haver sido organizacionais e espirituais; num segundo momento, políticas, e, no terceiro momento, relacionadas a problemas de moralidade pessoal; o fio condutor desse rompimento, entretanto, é que ele traz como conseqüência um reviver da religiosidade interior que compele os indivíduos a um maior envolvimento físico e pessoal.

Entretanto, os tempos mudam e, apesar da existência de padrões cíclicos, em cada oscilação os altos e baixos acontecem em circunstâncias diferentes. Assim, a associação estatística entre categorias amplas, tais como tradições religiosas e associacionismo cívico, podem exagerar a sensação de que elas se reforçam entre si em igrejas e comunidades específicas, por causa da volatilidade da filiação religiosa, das instituições religiosas e das culturas religiosas no mun- 
do contemporâneo: em um mundo de laços familiares fracos e grandes fluxos migratórios, as pessoas mudam suas filiações religiosas, abandonando as dos pais, ou escolhem versões diferentes das religiões, às vezes tornando-se menos comprometidos, ou retornando a suas raízes e adotando uma versão mais rígida - freqüentemente para a infelicidade dos pais já mais secularizados -, ou até mesmo crescem na ignorância religiosa e optam por uma nova filiação na idade adulta. As tradições religiosas fragmentam-se sob várias influências, influenciando-se entre si, sob a pressão dos movimentos migratórios internacionais e das diferenciações internas em correntes liberais, carismáticas e fundamentalistas. Trata-se do bricolage relativizado de que nos fala HervieuLéger (2001), que é difícil, porém não impossível, de apreender com métodos estatísticos. Embora eles ofereçam, sem dúvida, sugestivas linhas de pesquisa, sua confiabilidade depende de categorias rápidas e duras que as bricolagens recusam-se a fundir.

Em total, é possível perceber que certos termos são usados inicialmente como se fossem algo que posteriormente mostram não ser: os evangélicos, à medida que ganharam força partindo das denominações mais importantes, inicialmente evitaram repetir as batalhas fundamentalistas do início do século XX, mas a linha entre evangélicos e fundamentalistas tornou-se mais e mais obscura, e ambas as culturas, aparentemente tão diferentes entre si, entrelaçaram-se à medida que começaram focalizar suas ações na direita cristã e nos debates políticos sobre moralidade pública e individual durante a década de 1980. Porém, a categoria "evangélicos" inclui uma minoria substancial de negros - e caberia perguntar-se em que medida eles seguiram essa tendência. Por trás da narrativa mise-en-forme de Hervieu-Léger (2005), a qual se encontra nas narrativas de conversão comuns a várias tradições religiosas (Lehmann, 1998), os movimentos de conversão tornaram as categorias mais instáveis do que os cânones religiosos estabelecidos.

Por exemplo, como vimos, Putnam classificou a Igreja católica e as igrejas evangélicas como hierárquicas, e voltadas para si, em oposição às denominações mais “congregacionais" - menos fundamentalistas e evangélicas. Eu não tenho certeza se essa classificação realmente funciona: já contrastamos a Igreja católica com as igrejas evangélicas em termos de seus graus de personalização e institucionalização da autoridade e, embora existam áreas mais obscuras dentro do catolicismo, a Igreja possui um aparato burocrático muito mais elaborado que as igrejas evangélicas, onde os pastores gozam de poder pessoal sobre seus membros e fiéis e estão sujeitos a escasso controle burocrá-

Horizontes Antropológicos, Porto Alegre, ano 13, n. 27, p. 69-98, jan./jun. 2007 
tico. Embora a burocracia eclesiástica seja pouco transparente - e em anos recentes seu caráter secreto e protecionista tem vindo à tona em circunstâncias embaraçosas e até chocantes - é, contudo, claramente mais institucionalizada que as igrejas evangélicas e pentecostais. Wuthnow (1988) situa os católicos em algum lugar entre os protestantes tradicionais e os evangélicos, no que diz respeito à sua participação em atividades voluntárias. Mas dentro do catolicismo, o crescente Movimento de Renovação Carismática, embora se aproxime muito dos pentecostais, permanece dentro do catolicismo e, de fato, encontrou no papa João Paulo II um grande simpatizante, quem supostamente foi cativado pela atmosfera social conservadora que rodeia as práticas carismáticas. ${ }^{4}$ Esse é um exemplo de fertilização cruzada entre tradições religiosas, e poderíamos mencionar muitos outros, - como, por exemplo, a influência do cristianismo fundamentalista nos judeus “revivalistas” (Lehmann; Siebzehner, 2006) e o crescimento da ala evangélica dentro da Igreja da Inglaterra.

\section{Quantidade versus qualidade}

Torna-se agora necessário reformular a questão inicial, sobre o papel aparentemente solitário dos movimentos e organizações religiosas enquanto construtores de instituições em contextos circunstanciais difíceis. Em primeiro lugar devemos enfatizar a palavra "instituições": a questão para um cientista social não é apenas o sucesso surpreendente das igrejas em se construírem, senão a impressão que elas conseguem transmitir de serem instituições únicas, e que se destacam quando comparadas à aparente fragilidade das instituições estatais e à fraqueza da sociedade civil. Mas são, de fato, as igrejas instituições em construção, diferentemente das organizações grandes e vivas?

Em segundo lugar, nossa discussão introdutória aponta para a importância de analisar como as diversas formas de autoridade religiosa afetam a produção e manutenção do capital social. A palavra “autoridade” é menos aconselhável porque é esse o fator subjacente ao que Putnam (2000) e Wouthnow (1988)

4 É possível perceber a crescente difusão das práticas carismáticas - seu estilo de cantar, suas gesticulações direcionadas a Deus, sua poliglossia - aos cultos celebrados nas igrejas paroquiais comuns, sendo que algum tempo atrás tais práticas eram confinadas aos cultos do Movimento Carismático apenas. (Observações em Campina Grande, Brasil, 2003).

Horizontes Antropológicos, Porto Alegre, ano 13, n. 27, p. 69-98, jan./jun. 2007 
referem-se ao usar a palavra “denominação”: variações de confiança entre os líderes e os fiéis, variações no grau de dependência pessoal que governa essas relações.

As opiniões generalizadas sobre todos esses assuntos não põem em questão nem levam em conta o fato de que, na América Latina especialmente, os únicos movimentos bem sucedidos são o dos pentecostais e seus primos católicos, o Movimento Católico Carismático (Chesnut, 2003).

Bem sucedido, nesse caso, significa logicamente pouco mais do que "de rápido crescimento”. Então agora é o momento de escavar mais fundo e colocar as bases para perguntar coisas sobre a verdadeira contribuição desses movimentos, tão rapidamente crescentes, para a criação do capital social, para posteriormente compará-los a seus concorrentes menos dinâmicos.

David Martin (2001) e os teóricos da escolha racional disseram repetidamente (Stark; Finke, 2000) que as igrejas mais institucionalizadas repousam freqüentemente em uma vida associativa escassa. Elas são descritas como tendo uma vida burocrática agonizante quando comparadas aos movimentos de renovação e retorno, e são um exemplo de religiões “quentes” (devemos admitir que Stark e Finke dissimulam melhor sua aprovação que Martin) que mobilizam centenas ou milhares de fiéis. Mas a história não termina aqui. Até mesmo uma burocracia agonizante pode ser herdeira de capital social, e esse tipo de capital, embora não muito ativo, por haver sido construído com esforço não desaparece tão facilmente - diferentemente do capital financeiro (Coleman, 1988). Podemos ver isso na curiosa legitimidade da Igreja da Inglaterra, a qual, apesar de ter um número de fies e contribuições financeiras cada vez menor em muitos lugares, ainda continua sendo uma parte importante da cultura inglesa e, de fato, da cultura anglo-falante em todo o mundo, ${ }^{5}$ de tal forma que o público que não vai à igreja e a mídia irreverente expressam opiniões veementes sobre assuntos tais como a vida sexual dos sacerdotes e se um herdeiro ou herdeira ao trono deveria ou não casar-se com uma pessoa divorciada. Devemos ser cautelosos ao julgar a contribuição das igrejas e movimentos ao capital social simplesmente com base nos tamanhos de seus comícios ou do público que assiste aos cultos, ou mesmo no número de seus templos dentro e fora dos

5 Como o mostram os ferozes debates sobre casamentos entre pessoas do mesmo sexo e a existência de sacerdotes homossexuais através das comunidades anglicanas no mundo todo.

Horizontes Antropológicos, Porto Alegre, ano 13, n. 27, p. 69-98, jan./jun. 2007 
grandes centros urbanos. O capital social é mais do que a soma de altruísmo e esforço coletivo - deve-se levar em conta, também, que o que é considerado altruísmo é, às vezes, uma combinação de altruísmo e outras motivações, tais como promessas de premiações e o temor de certas punições.

Além disso, existe o risco de fazer inferências inconseqüentes: o que, de fato, estamos querendo descobrir? Pretendemos saber se as instituições refletem o capital social, incorporam o capital social ou produzem capital social?

Se a condição de existência do capital social é seu potencial infeccioso, então a verdadeira pergunta pode não ser se as organizações religiosas (ou seja, o lado burocrático e institucional das religiões) constituem o capital social, senão se elas não dão origem a outras organizações capazes de criá-lo, tais como as Comunidades Eclesiais de Base, ONGs, escolas, ordens religiosas e instituições médicas. A Igreja da Inglaterra pode estar em sua fase terminal, mas, de uma forma ou de outra, ela elaborou uma boa parte do sistema educacional britânico, e a Igreja católica é responsável pela assistência à saúde e pela educação em muitos países, assim como o cristianismo inventou o secularismo. [Um dos motivos pelos quais foi definido um espaço para os leigos teve origens teológicas na cristandade (Taylor, 1998)].

\section{"Circunstâncias desfavoráveis"}

Construir uma instituição significa formular e implementar uma série de regras e rituais que estabelecem e protegem as fronteiras, outorgam previsibilidade e interação aos rituais e garantem confiabilidade. Isso pode parecer algo básico, mas no que concerne à religião, toca áreas muita sensíveis. A religião determina os rituais de passagem, assim regulando a vida sexual de seus fiéis. Enquanto instituição que se envolve em assuntos tão íntimos, ela difere de outras instituições por transitar entre as esferas pública e privada de formas que ser totalmente transparente e moderno é freqüentemente impossível. Outras instituições, tais como a medicina ou o direito, também transitam por ambas as esferas, mas, enquanto que médicos e professores devem aplicar tipos específicos de conhecimento a áreas específicas da vida íntima das pessoas, sob condições e regras especificadas, igrejas e seitas, pastores, sacerdotes ou rabinos vêm-se na necessidade de dar instruções sobre assuntos muito diversos, estando sujeitos apenas às próprias regras; mais do que isso, quando as pessoas consultam sacerdotes, pastores ou rabinos, ou quando se submetem 
à sua autoridade, confiam nela por suas qualidades inatas - daí a palavra "carisma”, que se refere a qualidades recebidas mediante um procedimento mágico. Tais qualidades, e não suas qualificações ou formação profissional, conferem aos sacerdotes e pastores uma autoridade sem limites sobre os fiéis; a confiança depositada neles é freqüentemente ilimitada. Logicamente, muitas instituições religiosas, especialmente as mais convencionais, hegemônicas e respeitáveis, colocam limites. Mesmo assim, até nas mais ponderáveis, resta um tanto dessa autoridade carismática, como o mostram alguns dos escândalos mais recentes. Mais do que isso, parece que os mais dinâmicos movimentos contemporâneos - os cristãos evangélicos, os movimentos judaicos t’shuva (retorno) e até mesmo os fundadores do West Bank, são os que colocam a maior quantidade de autoridade nas mãos dos líderes religiosos, sendo que muitos desses líderes autodenominaram-se como tal.

Em alguns movimentos, grandes poderes encontram-se nas mãos de indivíduos, os quais têm a liberdade de diagnosticar casos de possessão e conduzir exorcismos. É o caso, por exemplo, dos rabinos, cujo aconselhamento é requerido para todo tipo de situação, desde a escolha de um parceiro de casamento até decisões concernentes a negócios e empresas. Geralmente, oficiantes menos institucionalizados têm poderes mais irrestritos e envolvem-se nas vidas pessoais e familiares dos fiéis, sendo esse um tipo de relação que não é compatível com uma relação de confiança baseada em normas preconcebidas.

O atravessamento não controlado das fronteiras entre o público e o privado vai junto a certo grau de fechamento e esoterismo. As organizações religiosas não poderão nunca, talvez, ser inteiramente abertas. Em um sentido trivial, nenhuma instituição é inteiramente aberta, pois todas colocam condições à entrada, pertença e proteção. Mas as diversas religiões condicionam o ingresso de seus possíveis fiéis de formas muito diversas: as instituições cristãs, até mesmo aquelas cujos fiéis são, em sua maioria, nascidos dentro da fé, requerem deles que se submetam a certos rituais ou passem por certas performances ritualísticas a fim de se tornarem membros - batismo como mínimo, mas também alguns procedimentos mais elaborados, como no caso dos pentecostais, os quais exigem que seus fiéis se ajoelhem em público e “aceitem a Jesus” e, em alguns casos, o batismo por imersão. Em certo sentido, tais rituais de passagem envolvem ou invocam o sobrenatural. No judaísmo, o sobrenatural não é invocado porque a entrada acontece no nascimento e a conversão é um processo de aprendizado, não um ritual. Isso significa, logicamente, que a religião não é 
uma instituição aberta, e que, de fato, a criação e manutenção de certas fronteiras tem uma importância central para as instituições e movimentos religiosos. Nas seitas e movimentos evangélicos mais dinâmicos, os rituais de ingresso tornam-se cada vez mais elaborados e são equivalentes ao estabelecimento de fronteiras, mesmo que não sejam codificados e que sejam escassamente mencionados. Os judeus secularizados que mudam de vida e optam por retornar à observância estrita, ou à ultra-ortodoxia, mudam suas formas de vestir, as formas de andar, falar e viver, seus trabalhos, e assim por diante, até terem eliminado todas as reminiscências e relações com a forma de vida anterior. Em ambos os casos, existem muitos estágios pelos que uma pessoa deve passar entre - no caso dos evangélicos - ser um participante regular dos cultos e “aceitar a Jesus”, pagar pelos pecados, receber os dons do espírito (poliglossia, o dom da oratória e assim por diante ${ }^{6}$ ), sendo-lhes confiados pequenos trabalhos como varrer a igreja, ensinar na escola dominical, cuidar dos corredores do templo durante o culto, pregar, etc. ${ }^{7}$ Os judeus que retornam ao judaísmo precisam também passar por uma série de estágios, especialmente estágios generacionais, antes que possam casar seus filhos com famílias ultra-ortodoxas de longa data. ${ }^{8}$ Os adeptos nascidos na comunidade ultra-ortodoxa passam por uma série de estágios mudando de hábitos em momentos específicos de suas vidas; passam do uso de um tipo de chapéu para o outro, de um tipo de manto para rezar para outro, assistem aos rituais de banho apenas depois do casamento, etc., etc. As mulheres assistem aos rituais de banho após o casamento mensalmente, entre outras coisas.

Todos esses rituais traçam e reforçam fronteiras e, portanto, fecham a organização aos outsiders. O ethos “divulgacionista” dos evangélicos abre certas portas, mas não abre a organização; pelo contrário: os mais evangélicos (a seita judaica Chabad-Lubavitch e a Igreja Universal Pentecostal do Reino de Deus) são as que melhor guardam seus segredos. Os pesquisadores tornam-se cientes disso ao perceberem que certos assuntos - especialmente os relativos a dinheiro, política interna da igreja e a tomada de decisões - ficam

6 Coríntios 12:8-10: sabedoria, conhecimento, fé, os dons da escuta, dos milagres, da profecia, do discernimento de espíritos e da interpretação de línguas.

7 Um padrão observado no Brasil durante a década de 1990, especialmente na Igreja Universal do Reino de Deus.

8 Observações realizadas em Israel e na zona norte de Londres entre 2003 e 2005.

Horizontes Antropológicos, Porto Alegre, ano 13, n. 27, p. 69-98, jan./jun. 2007 
fora dos limites da investigação e ao perceberem quão difícil - quase impossível - é simular pertença à religião. Mesmo onde a forma de vestir não é um distintivo de pertença, os outsiders destacam-se e são conscientes de sua posição de destaque.

Tais mecanismos de fechamento não são coerentes com um modelo da sociedade secular segundo o qual as organizações religiosas assemelham-se a outros tipos de organização, supostamente abertas ao escrutínio e operando na base das regras impessoais. Aqui a autoridade é pessoal, especialmente quando se trata de cura e de exorcismo, de tal maneira que a forma de gerar capital social, apesar do grande comprometimento dos fiéis, está em dúvida por razões que surgem de suas características centrais. Isso se aplica especialmente aos movimentos evangélicos, os quais, precisamente, brotam em situações difíceis.

É notável, sobretudo, que os seguidores dos movimentos evangélicos cristãos e fundamentalistas judaicos pareçam mais dispostos que os membros das religiões mais institucionalizadas a fazerem doações generosas, especialmente quando se leva em conta seus magros recursos. Embora esses movimentos evangélicos e fundamentalistas sejam muito fechados, eles são capazes de gerar uma grande lista de organizações para seus fiéis, e tais organizações operam em bases racionais: entre as escolas judaicas ultra-ortodoxas, trabalhos de caridade, asilos para anciãos, centros comunitários que oferecem, por exemplo, taxas fixas para cerimônias de casamento, sociedades rotativas de crédito (gemachim) ${ }^{9}$ em uma grande escala. A Igreja Universal faz trabalhos sociais; no Brasil dedica-se à educação, em parceria com os governos municipais e estaduais (Birman; Lehmann, 1999). Pareceria tratar-se de um grande capital social, mas será que, de fato, aumenta o capital social disponível na sociedade em geral? Não era o ponto principal da teoria de Putnam que, de alguma forma, a vida associativa e os modos de interação que ela estimula são benéficos não apenas para os diretamente envolvidos, mas para a sociedade em geral, principalmente para a construção de instituições?

Podemos ilustrar esse ponto apontando para como as sociedades de crédito rotativo funcionam na base de um delicado equilíbrio entre confiança e fofoca: embora os empréstimos não estejam assegurados em fundos, eles são garantidos por indivíduos e registrados em um documento legal: o indivíduo que

9 Um acrônimo de gemlut chasadim - atos de cordialidade 
não cumpre com suas obrigações legais terá problemas com o fiador e com os outros membros da comunidade. Isso somente pode funcionar dentro de uma comunidade de rede estreita. A contribuição da religião e capital social, portanto, pode bem ser uma questão de equilíbrio entre o interno e o externo, entre o público e o privado, entre a abertura e o fechamento na relação entre os potenciais fiéis de uma organização ou movimento e os outsiders.

\section{Escolha racional}

A explicação sociológica freqüentemente olha para as características mais amplas (modernidade, desigualdade, público - a lista é obviamente muito longa) a fim de dar conta de aspectos particulares tais como capital social, confiança, o crescimento de algumas igrejas e não de outras, fundamentalismo religioso. As interpretações dos movimentos religiosos contemporâneos tendem a ser do tipo genérico, baseadas na idéia de que o ambiente social oferece um nicho confortável capaz de abrigar tais movimentos: um nicho de identidade, um nicho de modernidade, um nicho de contestação social, etc.

Embora essas explanações não estejam necessariamente erradas, elas podem ser frustrantes. Elas oferecem proposições gerais que são difíceis de aplicar em situações particulares. Em outras ocasiões, eu optei por uma análise desde uma perspectiva mais geral, (Lehmannn; Siebzehner, 2006) como já o fizeram também outros (Sperber, 1996); portanto, agora explorarei a utilidade de uma narrativa que relacione religião e capital social partindo do indivíduo e da vida cotidiana. Evitarei, entretanto, argumentar agressivamente contra as abordagens macro, já que essas estão enraizadas na tradição do argumento sociológico.

Os movimentos religiosos em que estamos interessados dependem da participação ativa e continua dos fiéis, aos quais colocam grandes exigências; é essa a participação que está em questão no debate sobre o capital social. Se sua participação é passiva, ou intermitente, não reforçará o tipo de vida associativa que supostamente será responsável pela criação de um capital social. De fato, como os teóricos da escolha racional não cansam de nos lembrar, a religião dificilmente pode existir sem colocar exigências aos seus fiéis individualmente. Além disso, um dos aspectos em que os movimentos religiosos variam está relacionado ao tipo de exigências que fazem de seus fiéis, abrangendo tanto aqueles que envolvem todo seu séqüito no manejo e administração da igreja, e 
que reconhecem dádivas do espírito mesmo entre os mais humildes, como aqueles que tratam seus fiéis quase como clientes de um supermercado.

A teoria da escolha racional oferece uma explanação possível e parcimoniosa de por que alguns movimentos religiosos e organizações são bem sucedidos em geral e em "circunstâncias difíceis”, o que constitui o ponto central da questão. Focaliza nas razões pelas quais aquelas organizações religiosas que impõem as maiores demandas a seus seguidores parecem atrair e reter 0 maior número de fiéis. A resposta é que tais organizações oferecem benefícios a seus fiéis na forma de caridade e solidariedade, e para mantê-las é necessário um esforço coletivo. Os sacrifícios impostos aos fiéis garantem que unicamente os verdadeiros crentes se tornem membros da igreja, fazendo também que os oportunistas sintam-se rapidamente desencorajados (Berman, 2000; Iannaccone, 1998). Tais explicações evitam as escolhas ideológicas, e focalizam a vida diária das pessoas envolvidas. De fato, seria melhor se essa abordagem fosse denominada de "abordagem do cotidiano", pois enfatizar a palavra "racional” pode levar as pessoas a pensarem que o que está sendo defendido é um conceito de religião como uma experiência racional. Eu prefiro vê-la como uma abordagem que privilegia as estratégias adotadas pelos indivíduos em suas vidas diárias e não enfatiza a ideologia ou a crença - apesar das empatias religiosas de alguns de seus defensores. De fato, um dos méritos dessa abordagem é precisamente que ela não requer que o intérprete faça sempre suposições incertas sobre a relação entre as crenças que seus fiéis dizem ter e suas ações.

A abordagem da escolha racional pode não ser a chave para explicar todo comportamento religioso: o fato que muitas religiões populares que não mantêm um viés teológico tão forte nem são institucionalizadas ainda sejam responsáveis pela vida religiosa de muitas pessoas pode melhor ser explicado mediante uma abordagem cognitiva (Atran, 2003; Boyer, 2001). Que muitas religiões menos rígidas e mais liberais também dêem conta da religiosidade das pessoas pode ser explicado tanto por uma abordagem cognitiva quanto mediante a teoria da escolha racional, mantendo suas raízes apenas nos rituais e no ritmo das convenções. Mas a escolha racional parece funcionar bem quando os benefícios dos membros do "clube” (termo usado pelos economistas) são materiais e observáveis: por exemplo, em Israel, onde os subsídios diretos e indiretos do governo vão para as instituições do judaísmo ultra-ortodoxo, e onde os homens estudiosos da Torá de tempo integral estão livres do serviço militar, os líderes das instituições do judaísmo ultra-ortodoxo (os yeshivot ou os líderes dos centros de estudo e as autoridades do chassidismo dinástico ou quase dinástico 
conhecidas como rebbes) precisam tomar medidas que garantam que aqueles que se beneficiam de tais condições sejam sinceros em sua adesão. Com os chassidim existe uma divisão de trabalho entre aqueles que estudam ou se dedicam em tempo integral às atividades religiosas e aqueles que realizam negócios. Os últimos fazem grandes doações às instituições religiosas, portanto, a liderança deve também ter certeza de que tais doações sustentam apenas os verdadeiros crentes. Os pentecostais da América Latina, e talvez de todas as partes, têm uma ótima reputação de funcionários honestos e trabalhadores, por isso devem se proteger contra impostores. Tal proteção é ajudada (embora não exatamente causada) pela imposição de códigos de vestimenta muito austeros, como acontece no chassidismo e em outras instituições judaicas ultra-ortodoxas. A igreja brasileira Deus é Amor (Lehmann, 1996) apresenta um exemplo extremo de código de vestimenta austero, mas outras fazem o mesmo em menor grau. Todas as igrejas pentecostais, desde as grandes federações às pequenas capelas, exigem dízimos e às vezes doações maiores do que o conhecido $10 \%$ dos rendimentos mensais: algumas delas fazem isso de forma muito pública, durante os cultos, outras fazem-no mais discretamente.

Nesse ponto devemos lembrar que as organizações religiosas são realmente diferentes entre si: os benefícios da religião (salvação, cura espiritual, vida eterna, paz espiritual, a superação da infertilidade) são inerentemente incertas e intangíveis: tradicionalmente, os sociólogos preocuparam-se menos com os benefícios individuais da religião que com seus efeitos sociais e culturais. Os ativistas religiosos tentarão colocar seus fiéis e possíveis fiéis em uma situação onde suas escolhas sejam limitadas: por um lado, as limitações são leves, por outro, muito rígidas. As organizações obtêm sua capacidade de reforçar tais limitações de várias maneiras: controlando a reprodução e influenciando na educação das novas gerações, atraindo conversos até se tornarem dependentes da organização, obtendo recursos do Estado e alocando-os entre seus seguidores e nas atividades do movimento.

Portanto, as decisões feitas pelos judeus ultra-ortodoxos (conhecidos também como haredim) sobre suas vidas são profundamente afetadas pela enorme pressão sob a qual seus pais se encontram; esses devem enviar seus filhos a escolas haredim onde as habilidades necessárias para seguir uma carreira ou profissão convencional são excluídas do currículo. É especialmente dessa forma em Israel, onde tais escolas são financiadas completamente pelo Estado, embora, mesmo na diáspora, as disciplinas ensinadas em tais escolas sejam poucas e, portanto, poucas pessoas tornem-se médicos ou advogados. A maio- 
ria dos meninos torna-se estudantes da Torá de tempo integral e artesãos no tempo livre, ou dedicam-se aos negócios, enquanto que as meninas tornam-se professoras e freqüentemente sustentam a família enquanto o marido estuda. As autoridades rabínicas estabeleceram esse sistema de controle educacional com o objetivo de tornar difícil que os ultra-ortodoxos sigam carreiras seculares, ajudados pela pressão social e a fofoca, a qual também tem uma parte importante em manter as pessoas fora da vida secular. Apesar do controle dos fundos e a indisposição econômica de seus seguidores, eles conseguiram criar um sistema de dependência pessoal - não do tipo que espalharia capital social.

Assim, o poder é importante para estabelecer os parâmetros de escolha. Os líderes exercem o poder com o objetivo de limitar as alternativas ou de estimular o comportamento submisso, assim limitando as opções feitas por seus fiéis, enquanto o caráter inerentemente intangível e incerto das recompensas religiosas determina a forma como o poder é exercido.

Existem pressões por transparência também. Pessoas e instituições que doam fundos para uma comunidade religiosa querem provavelmente duas coisas (entre outras): uma delas é algum grau de confiança de que os fundos serão adequadamente gastos, e a outra, no caso dos indivíduos, é serem poupados das pressões de outros pedintes. No outro extremo, aqueles que estão na posição de se beneficiar dessa grandeza querem ter certeza, individualmente, de que irão de fato se beneficiar e de que outros não se beneficiarão indevidamente. Então, em um mundo perfeito, cada um tem um interesse de uma maneira racional, impessoal e altamente institucionalizada de distribuir os benefícios. Assim podem querer ter, como líder, uma pessoa que esteja disposta a fazer algum sacrifício, ou seja, algum rabino ou pastor com vocação de santo que, porque seu interesse pessoal não está em jogo, pode ter a confiança dos outros enquanto líder ou parceiro em um empreendimento cooperativo.

Os empréstimos feitos por sociedades de crédito rotativo são formais e legalmente reforçáveis, não estando baseados apenas em um aperto de mãos. Em casos de disputa, são julgados por um rabino cuja autoridade é aceita por ambas as partes. Paradoxalmente, isso reflete mais confiança: quando um mero aperto de mãos é suficiente, geralmente significa que uma das partes é tão poderosa que a outra pode sentir-se amedrontada, ao pedir um documento formal, de sugerir que a parte dominante (um proprietário de terra, ou um homem de honra) poderia não honrar o acordo. Em resumo, a parte mais fraca é intimada e a confiança é fraca. 
Mas o mundo não é perfeito, nem a informação tampouco o é. Embora os indivíduos saibam que podem decepcionar os outros e sejam conscientes de que se persistem nesse tipo de atitude a "base moral da vida comunitária" falhará (Atran, 2003, p. 117), há sempre um risco de que alguém tente "passar alguém para trás”. É por isso que as bruxas e a máfia, as quais vivem na e da decepção, e fazendo acordos “por baixo dos panos”, são um exemplo de algo que pode dar errado; mas é por isso também que são temidas por todos. É por isso também que poderes especiais são oferecidos a indivíduos carismáticos que não estão apenas preparados para fazer um sacrifício, mas que também dizem ter dons e poderes especiais de percepção.

Portanto, de alguma forma, o líder deve tecer uma delicada passagem entre a autoridade racional e o empoderamento sobrenatural. Se a balança pesa muito a favor do primeiro, a instituição perde suas qualidades sobrenaturais e se torna uma firma ou um aparato legal, algo que tem acontecido em larga escala com as igrejas européias. Se a balança tende muito para o outro lado, pode terminar se aproximando de cultos autodestrutivos, embora, mais provavelmente, não conseguirá se desenvolver e erguer-se e sucumbir com apenas um líder.

Podemos observar exemplos contrastantes entre a comunidade lituana de estudiosos do Talmude e a comunidade dos chassidim. Entre os lituanos, que se consideram a si mesmos menos supersticiosos e menos cativados pelas demonstrações físicas e emotivas de sua religiosidade, as figuras de autoridade são os líderes dos yeshivot e sua tendência é casar suas filhas com sucessores apropriados, dessa maneira evitando o risco de colocar suas organizações nas mãos de filhos duvidosos. Nas seitas dos chassidim, ao contrário, o principio é altamente dinástico, mas é equilibrado pela criação de numerosas organizações e comitês de aconselhamento que supostamente guiam e exercem constrangimento na rebbe. Os chassidim consultam o rebbe sobre tudo, sobre com quem casar, sobre com quem seus filhos devem casar, sobre que tipo de investimentos devem fazer, sobre que carreira escolher, sobre quanto dinheiro gastar em uma celebração de casamento, etc.; como o rebbe não pode lidar com as dezenas ou centenas de mensagens e consultas que a ele chegam a cada dia, deve ter um secretário. Mesmo assim, seu poder de liderança, por exemplo, para colocar um fim à situação de não ter descendência de uma mulher, é lendário.

As igrejas evangélicas provavelmente recebem menos do Estado ou de doações que as seitas e instituições judaicas que mencionamos, especialmente 
per capita, dado o grande número de seguidores. Sem doadores ricos e sem o apoio do Estado, a maioria delas depende mais das doações de seus fiéis, mas suas exigências não são tão rígidas quanto as dos judeus ultra-ortodoxos no que diz respeito ao estilo de vida dos fiéis. (embora, para ter certeza, devêssemos desenvolver uma escala de rigidez para as exigências relativas ao estilo de vida e testá-la junto aos fiéis). Não surpreende, portanto, que eles obtenham contribuições financeiras substanciais, geralmente descritas como $10 \%$ da renda (descontados os impostos, quando esses são importantes), embora pouco saibamos sobre como varia esse dízimo entre os países, classes e igrejas (os sociólogos, entre eles eu, parecem tímidos de lidar com a questão do dinheiro mais detalhadamente na religião). A qualidade pessoal da relação com o pastor varia muito, das igrejas onde ele ministra curas, exorcismos, diagnósticos e cuida das almas de forma muito pessoal, até outras onde observamos "liquidações” de exorcismos e curas - como na Igreja Universal do Reino de Deus, a qual criou um sistema para evitar que os pastores e pregadores se aproximem demais de seus séqüitos.

Tais manipulações conferem maior poder aos pastores: se uma cura for bem sucedida, a influência do pastor será maior, mais pessoas virão a ele e seus cofres ficarão mais e mais cheios. Mas freqüentemente o resultado é duvidoso, e as responsabilidades do curandeiro, exorcista e sofredor o são ainda mais: nesse ponto, o curandeiro joga com seu monopólio de acesso ao sobrenatural: pode ser que a cura tenha sido ministrada por um impostor ou por alguém que estava possuído; talvez até, o sofredor tenha estado escondendo algo ou os demônios tenham sido poderosos demais. Os xamãs e curandeiros possuem sempre um conhecimento superior, e, como muitas pessoas os consultam, conhecem muito sobre as vidas privadas dos moradores do lugar, dos membros da igreja e sobre a comunidade. É por isso que eles oferecem consultas sobre todos os assuntos. Os seguidores os consultam precisamente por possuírem informações estratégicas (Boyer, 2001) que poderão ajudar a descobrir quem são os responsáveis por seus infortúnios e a manter o medo das bruxas, demônios e maus espíritos e, portanto, também daqueles que dizem combatê-los.

O poder está presente nos níveis micro e macro. No nível macro há inúmeros exemplos: a Assembléia de Deus Africana em Zimbawe (Zaoga - a qual não necessariamente conta com o apoio das maiores Assembléias) parece, como outros casos, ser uma organização envolvida em enriquecimento pessoal e liderada por pessoas que flertam com os ditadores locais (Maxwell, 2001). 
$\mathrm{Na}$ Guatemala, a guerra civil alcançou seu ponto mais sangrento sob um ditador militar que pregava a palavra de Deus por rádio, e encorajava o exército a dividir os indígenas e camponeses em dois grupos opostos, o dos evangélicos “amigáveis" e o dos católicos (chamados de comunistas ou subversivos) (Le Bot, 1992), com conseqüências sangrentas e amedrontadoras.

Porém, ao mesmo tempo, os ultra-ortodoxos criaram instituições duradouras: isso é mostrado pelo renascimento do holocausto da cultura da ultra-ortodoxia no Ocidente europeu, nos Estados Unidos e em Israel, especialmente se comparados com os judeus do Norte da África e do Oriente Médio (Friedman, 1987; Lehmann; Siebzehner, 2006). Os últimos, em suas imigrações a Israel, Europa e América, não transplantaram suas instituições, porque em seus países de origem elas funcionavam dentro de um sistema clientelista, dirigidas pelos "notáveis", dos quais os rabinos dependiam, ao invés das elites rabínicas independentes (Deshen, 1989). O problema continua: a suntuosa sinagoga sefardi em Gênova, está atualmente sob disputa porque um indivíduo disse que é "sua” sinagoga, enquanto que se fosse uma sinagoga asquenaze, seria dirigida por um comitê e propriedade de uma comunidade, um corpo de caridade.

Não pretendo exagerar ou distorcer: esses exemplos de judeus ultra-ortodoxos envolvem uma grande quantidade de capital social, mas seus centros religiosos são aparatos não democráticos que carecem de decisão participativa: a autoridade rabínica é enorme e, mesmo que não seja necessariamente baseada em clientelismo, ela permite um envolvimento invasivo da autoridade religiosa na vida privada das pessoas. Há, além disso, uma grande riqueza de crenças concernentes ao mau-olhado, ao prejuízo provocado pela fofoca (a má língua) e o impulso para o mal. A autoridade não é verdadeiramente impessoal: a interpretação dos textos rabínicos visando a governabilidade é uma questão de juízo individual do rabino. Não se trata de uma jurisprudência semelhante àquela com que estamos acostumados no sistema de direito comum ou de direito romano.

Assim, mesmo onde a religião derrama solidariedade social generosamente, há ainda dependência pessoal e concentração de poder.

\section{Envolvimentos políticos}

Evidentemente, as seitas e instituições judaicas têm se beneficiado da riqueza sem precedentes da comunidade judaica mundial no período pós-guer-

Horizontes Antropológicos, Porto Alegre, ano 13, n. 27, p. 69-98, jan./jun. 2007 
ra e do apoio do Estado de Israel. As seitas evangélicas, pelo contrário, são bem sucedidas entre pessoas que vivem vidas de privações e com pouco capital de qualquer tipo, e freqüentemente em situações de dificuldades extremas. Esses são, obviamente, fatos estilizados que precisam ser entendidos com mais profundidade, mas eles refletem, mesmo assim, uma realidade que é suficientemente e amplamente reconhecida para que nos possamos explorar quais seriam suas possíveis implicações.

Em tais circunstâncias uma maior proporção de fiéis de uma igreja deve contribuir com seus próprios esforços e recursos. Isso pode parecer paradoxal, já que, sendo pobres, têm menos a dar, mas a escolha racional nos diz que os mesmos princípios da teoria do clube são aplicáveis. Os benefícios que eles recebem da igreja parecem menos tangíveis que os obtidos pelos judeus ultraortodoxos que discutimos anteriormente, mas pode ser que isso seja um conceito errado. As igrejas ajudam os fiéis a encontrar trabalho, os pastores se esforçam em manter-se em bons termos com os políticos, independentemente de ideologias, e sua capacidade de lhes oferecer um pequeno, porém consistente, grupo de votantes faz com que os políticos valorizem seu apoio (mesmo onde não há eleições livres) - por isso oferecem patrocínio político a seus cabos eleitorais.

O envolvimento de pastores evangélicos e rabinos de ultradireita na política é cada vez mais visível. Os ultra-ortodoxos garantiram sua representação no governo local de Hackney, e, em Israel, eles têm partidos políticos próprios e controlam o município de Jerusalém. Nas eleições de Israel, a bancada haredi alcançou 90\%, o que explica seu sucesso nas eleições locais onde a classe média secularizada tem resultados muito menores. No Brasil, o último Congresso obteve uma bancada de 80 membros, embora tenha diminuído drasticamente no ano de 2006 devido a envolvimentos em escândalos de corrupção. Em sistemas de representação proporcional (como Brasil e Israel), os líderes religiosos são valorizados por garantirem números consideráveis de votos. Tal tendência parece não ser benéfica ao potencial de capital social dos movimentos religiosos mencionado, direcionando a atenção aos benefícios materiais e ao patrocínio e a conseqüentes relações de dependência pessoal. Ao mesmo tempo, poderia levar os pastores e rabinos a acentuarem suas demandas de sacrifícios e abstinência por parte dos fiéis, já que quanto maior for o patrocínio maior será o risco de atrair oportunistas e impostores. 


\section{Conversão}

Um fator extremo e importante para explicar a participação continuada e a submissão a requerimentos rígidos nas seitas evangélicas pode ser o papel da conversão como sua raison d'être. Esse fenômeno das igrejas cujos membros são quase inteiramente responsáveis pelos convertidos é relativamente novo - isto é, do século XX - e também tem se espalhado para certas seitas judaicas (especialmente Chabad-Lubavitch e, em Israel, Shas) e para os movimentos islâmicos onde os conversos, embora, estritamente falando, retornem à sua própria herança pode ser considerado, tanto sociológica quanto psicologicamente, como convertidos. Isso ajuda o empoderamento dos pastores e, assim, ajuda-os também a impor um marco rígido às escolhas feitas pelos fiéis; tendo eliminado toda relação com o passado, os conversos são altamente dependentes de sua nova comunidade e estão ansiosos por mostrar prontidão para ajudar e contribuir. Bruce (1999, p. 137) apresenta dados para mostrar que a maioria dos conversos está, de fato, formada por migrantes de outras igrejas. Seus dados são, entretanto, relativos ao Canadá, ou seja, não a uma região de crescimento evangélico maciço como a África e a América Latina. Independentemente das quantidades envolvidas, ou, de fato, das nuanças da conversão, desde aqueles que nasceram dentro das famílias evangélicas, mas mesmo assim são "nascidos de novo" para serem completamente aceitos até aqueles que provêm de backgrounds totalmente seculares, o que devemos levar em conta é que, qualitativamente, a conversão é uma força impulsionadora nas seitas e movimentos evangélicos.

É possível que as altas proporções de conversos e "retornados” aumente a pressão pela busca de rigidez. Os conversos, se permanecem na igreja ou na seita - sendo que muitos não o fazem -, freqüentemente ficam ansiosos em relação às regras e costumes, e, portanto, tendem a procurar as alternativas mais rígidas, podendo também, coletivamente, pressionar os pastores e rabinos na mesma direção.

Carecemos de pesquisas que nos mostrem como o fator conversão influencia a criação de capital social. Em uma perspectiva, poderia se dizer que, ao atrair novos conversos e encorajá-los a cortar seus laços com sua vida anterior, as igrejas e movimentos evangélicos reduzem seu capital social; desde outro ponto de vista, seu proselitismo constante pode ser visto como uma forma de transmitir à sociedade um ethos de mobilização e dedicação. 


\section{Conclusão}

Este estudo distinguiu entre capital social e crescimento quantitativo, entre coesão interna de uma organização religiosa e sua contribuição ao aparato institucional da sociedade onde ela existe. Também distinguiu entre a institucionalização das instituições religiosas centrais e aquela das organizações que surgiram delas.

Além disso, discutiu o papel das circunstâncias desfavoráveis em que as organizações religiosas crescem rapidamente, chegando à conclusão que as organizações religiosas que crescem em tais circunstâncias podem não estar acrescentando capital social à sociedade, mesmo quando elas conferem poder a seus líderes e oferecem benefícios a seus seguidores.

A versão modificada da escolha racional apresentada aqui está baseada na idéia de que é necessário introduzir o conceito de poder a fim de oferecer uma boa explicação do funcionamento das igrejas e seitas evangélicas. $\mathrm{O}$ tipo de poder envolvido é invariavelmente pessoal e baseado na dependência pessoal, de tal forma que a contribuição das igrejas ao capital social é limitada.

Os exemplos perversos que trouxe (como Zaoga e Guatemala) devem ser considerados apenas como exemplos, e não casos típicos, escolhidos para ilustrar a relevância do poder no nível macro. A abordagem da escolha racional explica por que as pessoas se dispõem a fazer contribuições em dinheiro e tempo para construir igrejas. Pode-se aplicar essa abordagem nos bairros pobres das conturbações da América Latina e entre as populações rurais indígenas marginalizadas, bem como entre outros estratos sociais. As igrejas oferecem redes sociais enquanto amarram seus conversos em uma rede de obrigações e submetem-nos à autoridade pessoal dos pastores. Pode também explicar como na África, onde os evangélicos tendem a se encontrar em uma posição levemente mais alta na escala social (Garner, 1998, 2000; Meyer, 1998) conseguem se erguer entre os um pouco menos pobres e marginalizados que procuram proteção contra as pressões familiares e a violência cotidiana que ameaça engoli-los. As igrejas evangélicas podem criar capital social para seus seguidores, mas o estilo de autoridade e a importância das igrejas na consolidação das barreiras sociais entre seus membros e "o mundo", ou "o mundo das trevas”, como costumavam dizer meus entrevistados brasileiros, agem contra suas chances de criar capital social para os outros. De fato, é possível que exista algum tipo de teto quantitativo para a expansão desses movimentos em coletividades dadas: vale a pena notar que em nenhum lugar na América Latina 
os evangélicos ultrapassaram a marca dos $20 \%$, embora o teriam feito houvessem eles mantido as taxas de expansão que estavam conseguindo nas décadas de 1980 e 1990. Em Israel, se a comunidade judaica ultra-ortodoxa não experimentasse vazamentos, sua fertilidade somente (uma média 6,5 filhos para cada mulher fértil) teria garantido que ela ultrapassasse os $11 \%$, que é a estimativa máxima atual. Talvez exista uma compensação entre a grossura das fronteiras e a capacidade das lideranças de manterem o controle sobre seus seguidores.

O envolvimento cada vez mais visível dos cristãos evangélicos e líderes ultra-ortodoxos na política levanta uma série de questionamentos sobre sua força modernizadora, pois sua política é invariavelmente oportunista e não ideológica, sendo também em ocasiões venal, como pudemos ver recentemente no envolvimento de membros do caucus (bancada evangélica) nos escândalos do Congresso Nacional brasileiro.

Seria, de todas as maneiras, errado concluir com uma visão pessimista, pois não podemos deixar de reconhecer as boas ações das organizações de pastores e fiéis que constroem organizações eclesiais em meio à pobreza, exclusão social e, freqüentemente, ao caos e à violência. Essas pessoas mostram ter coragem e integridade para trazer esperança e até segurança a seus fiéis. As dúvidas expressas neste trabalho referem-se à sua capacidade de expandir seu capital social além de suas próprias organizações, e a possibilidade de que a construção de grossas fronteiras ao seu redor, embora possa ser a condição necessária a seu sucesso, evite que seus preciosos recursos alcancem outros setores da sociedade.

Traduzido do inglês por Daniel Angel Etcheverry Burgueño.

\section{Glossário}

Chabad-Lubavitch. Uma seita do chassidismo que experimentou um crescimento acelerado durante o período do pós-guerra e tornou-se líder do movimento t'shuva mundial.

chassidim (pl.) [hebraico]. Judeus ultra-ortodoxos seguidores da tradição mais mística de um movimento surgido no Leste Europeu no século XVIII e cuja religiosidade põe uma maior ênfase nas expressões religiosas corporais que os "lituanos"; os chassidim costumam reconhecer a autoridade de um único rebbe de origem dinástica; as seitas chassídicas são, em princípio, endógamas, embora não o sejam dogmaticamente. 
haredi (pl. haredim) [hebraico]. A tradução literal desse termo é "aquele que treme [perante Deus]”; o termo genérico é usado para referir-se aos judeus ultra-ortodoxos, entre os quais se encontram os chassidim e os lituanos, entre outros. Devem ser diferenciados dos judeus ortodoxos e dos que são atualmente chamados de "ortodoxos modernos".

lituanos. É o termo reservado, em principio, às pessoas treinadas nos yeshivot que seguem o método lituano de estudo, conforme ele foi desenvolvido por Gaon de Vilna (1720-1797). Na prática, o termo refere-se aos judeus ultra-ortodoxos não seguidores do chassidismo. Os lituanos estão também desenvolvendo certas características de seita, principalmente a endogamia.

rebbe [iídiche]. "Rabino"; termo usado especificamente para os líderes das seitas chassídicas.

Torá. Termo que, quando usado stricto sensu, refere-se aos Cinco Livros de Moisés, também conhecidos como o Pentateuco. É usado cotidianamente pelos haredim para se referir ao corpus do direito judaico e aos trabalhos escritos pelos rabinos. Ainda em termos mais genéricos, pode ser visto como referência ao estudo da lei judaica e da sabedoria, ou apenas como equivalente do termo "lei".

t'shuva [hebraico]. Arrependimento, retorno, ou inclusive resposta. Atualmente esse termo é usado para referir-se ao movimento do "retorno" a uma vida de observância religiosa por parte dos judeus secularizados.

yeshiva (pl. yeshivot) [hebraico]. Centro de estudos da Torá, assistido por jovens do sexo masculino, em princípio, antes de contrair núpcias. O termo é também utilizado para referir-se genericamente ao mundo de aprendizado da Torá.

\section{Referências}

ATRAN, S. In Gods we trust: the evolutionary landscape of religion. New York: OUP, 2003.

BERMAN, E. Sect, subsidy, and sacrifice: an economist's view of ultra-orthodox Jews. Quarterly Journal of Economics, v. 115, n. 3, p. 905-953, 2000.

BIRMAN, P.; LEHMANN, D. Religion and the media in a battle for ideological hegemony. Bulletin of Latin American Research, v. 18, n. 2, p. 145-164, 1999. 
BOYER, P. Religion explained: the human instincts that fashion gods, spirits and ancestors. London: Heinemann, 2001.

BRUCE, S. Choice and religion: a critique of rational choice theory. Oxford: Oxford University Press, 1999.

CHESNUT, A. Competitive spirits: Latin America's new religious economy. New York: OUP, 2003.

COLEMAN, J. C. Social capital in the creation of human capital. American Journal of Sociology, n. 94, p. S95-S120, 1988.

CORNWELL, J. The Pope in Winter: the dark face of John Paul II's papcy. London: Viking, 2004.

DESHEN, S. The Mellah Society: Jewish community life in Sherifian Morocco. Chicago: Chicago University Press, 1989.

FRIEDMAN, M. Life tradition and book tradition in the development of ultraorthodox Judaism. In: GOLDBERG, H. Judaism viewed from within and from without. Albany: Suny Press, 1987. p. 235-256.

GARNER, R. Religion and economics in a South African township. Ph.D. Dissertation. University of Cambridge, Cambridge, 1998.

GARNER, R. Religion as a source of social change in the New South Africa. Journal of Religion in Africa, v. 30, n. 3, p. 310-343, 2000.

HERVIEU-LÉGER, D. La religion en miettes ou: la question des sectes. Paris: Calmann-Lévy, 2001.

HERVIEU-LÉGER, D. Bricolage vaut-il dissémination? quelques reflexions sur l'opérationnalité d'une métaphore problématique. Social Compass, v. 52, n. 3, p. 295-308, 2005.

IANNACCONE, L. Introduction to the economics of religion. Journal of Economic Literature, v. 36, n. 3, p. 1465-1495, 1998.

INGLEHART, R.; NORRIS, P. Sacred and secular. Cambridge: Cambridge University Press, 2004.

LE BOT, Y. Guerre en terre maya: communauté, violence et modernité au Guatemala (1970-1992). Paris: Karthala, 1992.

LEHMANN, D. Struggle for the spirit: religious transformation and popular culture in Brazil and Latin America. Oxford: Polity Press, 1996. 
LEHMANN, D. Fundamentalism and Globalism. Third World Quarterly, v. 19, n. 4, p. 607-634, 1998.

LEHMANN, D.; SIEBZEHNER, B. Remaking Israeli Judaism: the challenge of Shas. London: Hurst and Co., 2006.

MARTIN, D. Pentecostalism: the world their parish. Oxford: Blackwells, 2001.

MAXWELL, D. African gifts of the spirit: fundamentalism and the rise of the Born-Again Movement in Africa. In: PERCY, M.; JONES, I. Fundamentalism: Church and society. London: SPCK, 2001.

MEYER, B. "Make a complete break with the past”: memory and post-colonial modernity in Ghanaian Pentecostalist discourse. Journal of Religion in Africa, v. 28, n. 3, p. 316-349, 1998.

PUTNAM, R. Bowling alone: the collapse and revival of American community. New York: Simon and Schuster, 2000.

PUTNAM, R. et al. Making democracy work: civic traditions in modern Italy. Princeton: Princeton University Press, 1993.

SPERBER, D. Explaining culture: a naturalistic approach. Oxford: Blackwell, 1996.

STARK, R.; FINKE, R. Acts of faith: explaining the human side of religion. Berkeley: University of California Press, 2000.

TAYLOR, C. The secular imperative. In: BHARGAVA, R. (Ed.). Secularism and its critics. New York: Oxford University Press, 1998. p. xii, 550.

VERBA, S. et al. Voice and equality: civic voluntarism in American politics. Cambridge: Harvard University Press, 1995.

WUTHNOW, R. The restructuring of American religion: society and faith since World War II. Princeton: Princeton University Press, 1988.

WUTHNOW, R. Mobilizing civic engagement: the changing impact of religious involvement. In: SKOCPOL, T.; FIORINA, M. (Ed.). Civil engagement in American Democracy. Washington: Brookings Institution Press, 1999. p. 331-364. 